\title{
Hollins University
}

\section{Hollins Digital Commons}

WRL Scholarship

Wyndham Robertson Library

5-15-2019

\section{The Design Cycle and a Mixed Methods Approach for Improving Usability: A Case Study}

James C. Miller

Hollins University, millerjc@hollins.edu

Follow this and additional works at: https://digitalcommons.hollins.edu/wrl_staff_fac

Part of the Library and Information Science Commons

\section{Recommended Citation}

James Miller (2019) The Design Cycle and a Mixed Methods Approach for Improving Usability: A Case Study, Journal of Web Librarianship, DOI: 10.1080/19322909.2019.1600451. Retrieved from https://digitalcommons.hollins.edu/wrl_staff_fac/1.

This Article is brought to you for free and open access by the Wyndham Robertson Library at Hollins Digital Commons. It has been accepted for inclusion in WRL Scholarship by an authorized administrator of Hollins Digital Commons. For more information, please contact lvilelle@hollins.edu, millerjc@hollins.edu. 
The Design Cycle and a Mixed Methods Approach for Improving Usability: A Case Study

\author{
James Miller \\ millerjc@hollins.edu \\ Hollins University
}

This is an accepted manuscript of an article published by Taylor \& Francis in THE JOURNAL OF WEB LIBRARIANSHIP on May 15, 2019, available online: https://www.tandfonline.com/doi/10.1080/19322909.2019.1600451. 


\begin{abstract}
This case study explores the concept of the design cycle as a guiding principle for choosing usability methods. It discusses the stages of the design cycle alongside the strengths and weaknesses of usability methods commonly used in libraries. Hollins University applied the design cycle principles to the redesign of the library's website, which involved various methods (e.g. analytics, card sorting, content audit, surveys and usability testing). This article argues that using the design cycle encourages an effective practice of mixing different usability methods, which leads to a more informed approach to improving usability. It concludes with recommendations for application of the design cycle to library projects.
\end{abstract}

Keywords: academic libraries, design cycle, mixed methods, website design, usability 


\section{Introduction}

"All of us are smarter than any of us" (Brown, 2009, p. 26).

The design cycle, also known as design thinking, is a user-focused and user participatory approach to problem-solving that can result in novel designs and a competitive advantage (Gibbons, 2016). It places an emphasis on the stages and methods used to discover a problem, generate solutions, test solutions, and then revisit the problem with the data acquired during the process.

The design cycle pursues the goal of improving usability by listening to users and observing user behavior through a variety of methods. This listening stage provides insights and sets the goals for the usability project. The users are the primary group engaging with the website or service so it is pragmatic that users define the problem and set the goals. Aside from defining goals, the design cycle can allow users to participate in creating solutions. These solutions to usability problems are tested, adjusted, and retested in the design cycle. The cycle is recursive so stages may be revisited and repeated for the same project. The design cycle has a sequence of stages and associated methods for each stage that provide direction, structure, and logic to any usability project.

The library staff at Hollins University, a small women's liberal arts college, wanted to redesign the library's website in concordance with our mission statement of "connecting our patrons with resources that advance scholarship and creative work" as well as "teaching students to thoughtfully engage in the discovery and use of information" ("Wyndham Robertson Library mission," n.d.). Applying the design cycle to a website redesign project aligned with our mission statement by striving to create a more usable website that supported our users' priorities. This case study details the stages of a website redesign project in the context of the design cycle and 
THE DESIGN CYCLE AND A MIXED METHODS APPROACH FOR IMPROVING

includes a discussion of design cycle principles. Included are sections for each stage of the design cycle, which list the methods typically associated with each stage and also provides guidance for choosing a method based on the nature of the usability project. The article concludes with recommendations for librarians interested in applying the design cycle to their usability project. The recommendations should scale for a usability working group or a single librarian working on a usability project.

\section{The design cycle as a concept}

The design cycle is also described as a design map, design method, design framework, design thinking, or development cycle. This article refers to this concept as the design cycle. There are many versions of the design cycle. One of the most well-known models is the five-stage model from the Hasso Plattner Institute of Design at Stanford University, whose stages are “empathize," “define," "ideate," “prototype,” and "test” (2010, pp. 2-6). Another prominent model is the International Baccalaureate, whose four stages are "inquiring and analyzing," "developing ideas," "creating the solution," and "evaluating." (2014, p. 2). Despite the varying number of stages, the principles and ingredients of all design cycles are similar and models with fewer stages often bundle multiple processes into one stage. For instance, "empathize" and "define" are the first two stages from the Stanford model, which considers them to be two separate processes of understanding users in order to define a problem. These two processes are handled in the first stage of the International Baccalaureate model named "inquiring and analyzing." Schmidt and Etches break the design cycle into the stages "observing," "prototyping," "testing," and "implementing" (2014, pp. 151-153). This case study applied a three-stage design cycle model because I was the sole researcher and dividing the process into three stages was more efficient and streamlined the process. 
This paper will use Schmidt and Etches's terms when referring to stages of the project: observing, prototyping, and testing/implementing (2014). While Schmidt and Etches define the first stage of the design cycle as "observing”, Usability.gov calls it "plan" and "analyze" ("UserCentered Design Process Map," 2013) and the Nielsen Norman Group (Gibbons, 2016) uses the terms "empathize" and "define." This first stage deals with understanding users and recognizing their difficulties using a library resource (e.g. difficulty finding journals in a discovery system). This stage uses information from users to define the problem and in doing so gives direction for the project and may help to define its goals.

The second stage of the design cycle is called "prototyping" and "ideating" by Schmidt and Etches (2014) and the Nielsen Norman Group (Gibbons, 2016), while Usability.gov defines this stage as "design." This stage involves generating ideas to resolve the problem identified in the first stage. The ideas could, for instance, involve a change to a website or discovery system to decrease the difficulty of using a feature by making changes (e.g. providing a filter to restrict search results to journals). This stage is not strictly the domain of librarians or designers because users can share their design ideas for improvements to a project.

The third stage is defined as "test and refine" by Usability.gov or "testing and implementing" by Schmidt and Etches (2014) and the Nielsen Norman Group (Gibbons, 2016). In this final stage, users test the design ideas generated from the second stage. In other words, librarians test the prototypes created in the previous stage to see if they help resolve usability issues. Using the previous example of users having difficulty finding a journal, the activity in this stage might involve giving users journal-finding tasks on a prototype version of a website or discovery system. During this stage users give feedback about the prototype site designed to make finding journals easier. After this stage the design cycle practitioner modifies the prototype 
THE DESIGN CYCLE AND A MIXED METHODS APPROACH FOR IMPROVING

USABILITY: A CASE STUDY

based on users' reactions and actions during the test. After reviewing the findings from this stage, the prototypes are implemented or go "live."

The design cycle is often illustrated as a wheel, circle, or a flow chart of interconnected activities. It is illustrated this way to emphasize the concept of each stage of the design cycle informing the next stage. Moreover, the circular nature denotes there is no finish line in the design cycle as the "final" stage can lead back to the first stage. The design cycle is illustrated and structured in this cyclical way to encourage practitioners to run through the process multiple times. Repeating the cycle creates an iterative process of continually improving the user experience. Each stage of the design cycle provides insights and possible solutions to usability issues, so an understanding of the design cycle may help a librarian to improve the user experience.

Improvements to a library system may be suboptimal if stages of the design cycle are skipped. Skipping the "observing" phase means losing the opportunity to hear what users struggle with while using a library system or what changes users want. Deciding to skip the "testing/implementing" stage means making a change to the library system but not seeing how users react to the change before implementation. Users are involved in every stage of the design cycle. The beginning stage (observing) opens up communication with users about what they need. In the middle stage (prototyping), design cycle practitioners devise solutions and can involve the user in creating them. In the last stage (testing/implementing), users see prototypes and have the opportunity to engage with them, while practitioners listen to their reactions.

This paper examines how libraries can use the design cycle to apply a mixed methods approach to usability research. Usability methods may include surveys, focus groups, usability testing, content audits. A mixed methods approach is a "class of research where the researcher 
mixes or combines quantitative and qualitative research techniques, methods, approaches, concepts or language into a single study" (Johnson \& Onwuegbuzie, 2004, p. 17). This approach can be advantageous because it harnesses the respective strengths of qualitative and quantitative methods to gain more complex insights that single methods are unable to provide (Johnson \& Turner, 2003). Choosing combinations of methods can seem overwhelming based on the sheer amount of methods that exist. Using familiar methods, perhaps those from previous projects, is appealing, but this can create blind spots as each method has limitations in gathering data. This paper argues that following the design cycle can simplify the selection process because each stage of the cycle calls for different methods. See Table 1 for the stages of the design cycle and methods commonly associated with each stage.

Table 1. Design cycle stages and associated methods

\begin{tabular}{|l|l|}
\hline $\begin{array}{l}\text { STAGE 1 } \\
\text { Plan/Analyze } \\
\text { Observing } \\
\text { Empathize/Define }\end{array}$ & $\begin{array}{l}\text { METHODS } \\
\text { Analytics, Focus Groups, Interviews, } \\
\text { Personas, Surveys, Task Analysis }\end{array}$ \\
\hline $\begin{array}{l}\text { STAGE } 2 \\
\text { Design } \\
\text { Prototyping }\end{array}$ & $\begin{array}{l}\text { METHODS } \\
\text { Card Sorting, Content Audit/Inventory, } \\
\text { Parallel Design, Prototyping, Usability } \\
\text { Testing }\end{array}$ \\
\hline $\begin{array}{l}\text { STAGE } 3 \\
\text { Test and Refine } \\
\text { Testing/Implementing }\end{array}$ & $\begin{array}{l}\text { METHODS } \\
\text { First Click Testing, Heuristic Evaluation (aka } \\
\text { Expert Review), Usability Testing }\end{array}$ \\
\hline
\end{tabular}

It is common to divide methods into either a quantitative or qualitative category, but there are additional ways to categorize usability methods. The Nielsen Norman Group categorizes methods as attitudinal or behavioral, qualitative or quantitative, or contextual or decontextualized (Rohrer, 2014). These categories can be a useful framework for understanding the benefits and limitations of different methods. Seeing how different categories of methods counterbalance the 
weaknesses of other methods makes selecting a mix of methods easier. This article will not attempt an exhaustive treatment of all methods, but covers common methods used in libraries, based on a review of the literature.

Surveys are common in libraries and as a method are in the attitudinal category because they gather participants' thoughts about the website and are decontextualized because the survey is not done while actively interacting with the website. Classic usability tests, whereby a user attempts tasks on a website while thinking out loud and under the observation of a facilitator, are in the behavioral and contextual categories because they collect behavioral data while a participant uses the website. Applying a small number of different methods from different categories ensures a well-informed and holistic approach to improving usability. Moreover, seeing how these methods relate to, and can supplement, one another shows the possible benefits of a mixed methods approach for improving usability. The findings from one method can inform the implementation of another method. For example, a survey about a website reveals users' difficulty with a particular feature of the website and a subsequent usability test is designed to test that particular feature.

This article aims to show how to choose different methods based on the stages of the design cycle and the needs of the project. The hope is that this enables librarians to choose a variety of methods that complement each other and produce more reliable data for defining the goals and course of action for a usability project.

\section{Literature review}

Broadly speaking, there is scant literature about libraries and the design cycle. One of the few publications available is the design thinking toolkit for libraries created by IDEO, a global design company, with the Chicago Public Library and the Aarhus Public Libraries in Denmark ("Design 
Thinking for Libraries," n.d.). The toolkit covers each stage of the design cycle, as well as pitching a project idea to administrators, managing a project, and case studies from various settings such as dating apps, hospitals, public libraries, and school cafeterias. The case studies touch briefly on the methods used to reach a project goal. The toolkit uses a wide approach to project areas, which includes programs, services, space, and systems. It is helpful in unpacking the design cycle, but there is no close examination of a library-related project and how each stage of the design cycle guided the choice of methods for the project.

In the library literature, Manzari \& Trinidad-Christensen (2006) used a combination of heuristic evaluation and usability testing to reveal different usability problems. Heuristic evaluation judges the library's website against a list of recognized usability principles. Rogers and Preston took a "multilateral approach" (2009, p. 202) using surveys, focus groups, usability tests, and card sorting. Two studies (Carter et al., 2005; Oldham, 2008) began their projects using a combination of methods (focus groups and a usability consultant) that later informed their design and use of classic usability testing. Zaugg, Terekhova, and Rennick (2015) conducted three levels of assessment (focus group, survey, and usability test) and each method informed the design and use of the subsequent method.

These papers do not mention the terms "design cycle," "design thinking," or "design framework", but these studies do contain a semblance of the design cycle. For instance, using a focus group and survey are forms of "observing", then using their findings to design a usability test is a form of "prototyping", and conducting usability testing is a form of "testing/implementing."

The greatest variety of usability of methods was used by Florida International University (FIU) Libraries in a series of four website redesigns between 2001 and 2014 (Dominguez, 
Hammill, \& Brillat, 2015). Their design methods included focus groups and analytics (a form of observing), think-aloud usability testing (testing/implementing), and content audits and card sorting (prototyping).

This review of the literature suggests that although many libraries are using a mixed methods approach to usability testing, which is a tenet of the design cycle, few or none are using the design cycle as a guiding principle for selecting the methods. The cited articles answer the question of how they gathered data for a usability project, but many do not discuss the rationale for choosing each method. Rogers and Preston (2009) and Zaugg et al. (2015) mention usercentered design principles, however there is no discussion of how these principles drove the selection of methods for their projects. None of the articles, aside from the design thinking toolkit from IDEO, discuss the design cycle as a guiding principle for choosing usability methods to apply to a project.

Outside of libraries, there are examples of explicitly and intentionally applying design thinking and the design cycle to usability problems. Toyota redesigned its Customer Contact Center by using journey maps and interviews about internal processes (observing), including Contact Center associates in the process of sandbox redesigns (prototyping), and testing the new system with customer inquiries (testing/implementing) (Liedtka, King \& Bennett, 2013). The redesigned website enabled associates to resolve customer inquiries with fewer calls and less time on hold, and in doing so saved money by enabling their associates to answer more customer inquiries. Kalaichandran (2017) describes the crowding of a hospital trauma area with nurses, physicians, and respiratory therapists, and how this high number of staff made it difficult to determine which staff member was leading the trauma team for each patient. Through simulating a scenario of a gunshot wound victim entering a fully staffed trauma area (observing), a nurse 
THE DESIGN CYCLE AND A MIXED METHODS APPROACH FOR IMPROVING

USABILITY: A CASE STUDY

came up with the idea (prototyping) that the leader of the trauma team wear an orange vest so others can see who is in charge (2017). This simple change led to more effective communication among staff (testing/implementing). Both of these case studies outside of libraries show the value of observing the problem, cultivating empathy for those affected (e.g. Contact Center associates and nurses), and allowing the affected individuals to participate as co-creators in devising a solution.

\section{Profile of the library}

Hollins University is a small women's liberal arts college with an FTE of approximately 650 undergraduate students, 150 co-ed graduate students, and nine full-time library staff with one staff member in charge of web services. Primary interactions between library staff and library patrons occur during instruction sessions (averaging over 100 per year) and Reference desk hours (roughly 450 hours per year). The library also has a Student Advisory Board, which allows students to play a role in library operations by providing feedback about services, collections and programs. The library's website and discovery system are common topics for the board's discussions. Specifically, the board has provided feedback during the process of changing our ILS providers from Millennium to Ex Libris and during the process of changing website platforms from Dreamweaver to WordPress.

The library is dedicated to providing excellent customer service, in particular by making an effort to listen to our users. We wanted to follow an approach to redesign that would put the users' needs first and the design cycle provided a helpful set of principles to follow. The aim of the project was to use the design cycle to identify problems and improve the website from a user's perspective. 


\section{Stage 1: Observing}

The observing stage gathers information about users in order to articulate goals for the project. Put simply, this stage is learning about a problem. Acknowledging previous reported problems is important in the observing stage. Known problems should be investigated in this stage, but whichever method chosen should also allow respondents to report new or unanticipated problems. For instance, a survey designed to uncover new problems could have questions about finding books and articles but also include an open-ended question prompting students to share experiences with tasks on the library's website that they find difficult. Exploring solutions to known problems may be categorized as "confirmatory" research, while deploying methods strategically to discover new problems may be categorized as "exploratory" research (Jaeger \& Halliday, 1998). Regardless of the stage of the design cycle, usability methods should strive to combine elements of confirmatory and exploratory research.

Depending on the project, certain methods may be more suitable for observing users. If observing or defining a problem involves an extended conversation about a topic with unspecified problems (e.g. student attitudes to ebooks), this requires a deeper dive than a survey or an analysis of analytics data. For this kind of topic, the methods of interviewing or conducting a focus group are more appropriate, allowing a librarian to pose questions and then probe deeper with different questions based on the responses. Conversely, if the goal is narrower than the ebook topic (e.g. evaluating how users feel about one small change to the homepage, such as adding a dropdown menu to a search box), then a survey focused on that particular change may provide valuable information. In any case, the observing stage contains an empathy component, which means librarians have to step away from their perceptions of a problem and allow their approach to a problem to be shaped by the needs and preferences of users. 
In the Wyndham Robertson Library observing phase, the problem was a cluttered homepage. When asked informally in instruction sessions about the library's homepage, students commented about the website being "too busy" or "crowded." Instead of removing content from the page without user input, library staff decided to survey students in the fall of 2015 about the layout of the homepage. This was "confirmatory" research because library staff were aware of the perceptions of the homepage. The survey also posed general questions about using the website, which was "exploratory" research designed to discover unknown issues.

We chose a survey as a method because it was easy to deploy to a large number of people and it allowed users to respond without the influence of a librarian who may have different rankings of importance for items on the homepage. In an interview or focus group, people "bend the truth to be closer to what they think you want to hear or what's socially acceptable" (Nielsen, 2001, para. 3). Surveys have the weakness of being a self-reporting method. In self-reporting, participants tend to over-report behaviors seen as appropriate or desirable (Donaldson \& GrantVallone, 2002). However, we believed that our survey would be less affected by this bias than focus groups or interviews.

One goal of the homepage survey was identifying low-priority resources and links for possible removal. The library's homepage had a box at the top of the page that included tabs and search boxes for the catalog, "Articles \& Databases", "eBooks”, "Frequently Asked Questions", and "Reserves." Below the tabbed search box were two sets of links under the headings "FIND" and "QUICK LINKS". In the first half of the survey, we asked respondents to rank the search box tabs and links from most important to least important. Allowing users to assign rankings and values was intended to show them their point of view was important and to communicate empathy. 
The second half of the survey included general open-ended prompts (e.g. "Complete the following sentence. On the library website I can never find...”). These prompts allowed respondents to comment on their overall experience using the site so the data we collected was not limited to the homepage. As noted, questions for surveys, focus groups, or interviews should give the respondent latitude to bring up problems not anticipated by the researcher. This allows the research to be exploratory.

There were 61 respondents to the survey (95\% undergraduate, $2 \%$ graduate students, and $3 \%$ faculty). 24 responded to the question "On the library website, I would like to see...." and $21 \%$ requested easier access to databases from the homepage, in the form of a clearer and more extensive list of databases and $25 \%$ requested a layout or design that was easier to read (e.g. less text, more noticeable font, and fewer links). Database access and homepage layout were the most consistent themes identified in this question. There were 20 responses to the question "On the library website, I can never find..." and 20\% stated the interlibrary loan service, which was the most consistent response. Although less significant of a trend, the My Account feature was mentioned once in both the "I can never find..." and "I would like to see..." questions.

Naturally, there is no perfect method in the any stage of the design cycle, which is why using multiple methods in each stage is important. Surveys, like interviews and focus groups, are a form of qualitative and attitudinal data, describing users' self-reported behaviors. A survey may be valuable for assessing users' needs and primary tasks, even though it does not show how these tasks are being done, specifically where the pain points are located. Rubin and Chisnell explain that asking people what they usually do on a website is no substitute for watching them 
in a usability test, but surveys help "begin to understand the preferences of a broad base of users about an existing or potential product" (2008, p. 17).

In this stage of the project, we supplemented the survey with analysis of web analytics, a quantitative method. Web analytics can track and report in a limited way what users do on a website, and so fall in the observing stage of the design cycle. Analytics have the limitation of not explaining users' behaviors (Fagan, 2014). Nonetheless, supplementing attitudinal data, such as the previous survey, with analytics is a good protection against the biases in self-reporting or weaknesses in qualitative sampling. Web analytics can, for instance, control for an imbalanced sample such as our survey, which had a 3\% faculty response. Analytics data can be a supplement to any other usability method. Analytics data will not always corroborate or contradict a trend in surveys or findings from other tools, but it offers an additional empirical viewpoint. Similar to surveys, analytics can help prioritize which tasks or pages to focus on during the prototyping and testing/implementing stages of the design cycle. Goward (2012) argues that analytics data is the most important resource for prioritizing what to test.

To supplement our survey with analytics, we used Google Analytics and Crazy Egg to track website activity from August through November of 2015 while the survey was underway. A tool like Google Analytics can identify which pages of a website are most popular and which are rarely viewed. This data can be used to corroborate responses to survey questions such as "What's the number one reason you visit the library's website?" Crazy Egg is a web analytics tool that takes a screenshot of a web page and displays all clicks as a heat map. Crazy Egg is priced by number of "snapshots" or pages loaded with the software. In our project, the homepage was the only page loaded with the tracking software. 
Google Analytics showed the databases page was the second-most-viewed page and this was consistent with the survey responses. The Crazy Egg snapshot of the homepage showed the “Articles \& Databases" link (in a table in the center of the page) and "Articles" tab (in the tabbed search box) were the "hottest" with the highest click numbers. The click numbers for the links to "Books," "Course Guides," "Films" and "For Faculty" also showed high use of these pages. Crazy Egg revealed "cold" links in the center table that received few clicks, if any. The Crazy Egg visualization of activity on the homepage provided a strong basis for decisions about removing low-priority links.

Crazy Egg also showed the percentage of clicks for each element (e.g. image, link, text, form). This is useful data in light of the trends in survey results, which indicated certain links (e.g. Interlibrary Loan and My Account) were difficult to find. The "Interlibrary Loan" link received $1.28 \%$ of the total clicks on links from the homepage, which appeared to corroborate survey responses that it was difficult to locate. The "MyAccount" link received $8.21 \%$ of the total clicks on links from the homepage. These percentages can be used as a benchmark when checking a site after making changes.

Crazy Egg data revealed the "For Faculty" link was the fourth most popular link of the ten links in the center table and was an important link to keep on the homepage. The popularity of the "For Faculty" link was noteworthy because it exposed representational weakness in the survey. A weakness in the survey data collection was the overrepresentation of undergraduate students (95\% of respondents) and underrepresentation of other user groups such as faculty (3\%) and graduate students $(2 \%)$. Had we relied exclusively on the survey data, we might have removed this popular link. 
The results of analysis in the observing stage can inform the next stage (prototyping) of the design cycle and allow a design cycle practitioner to make strategic decisions to address the findings from the observing phase. It was clear from the results of our observing methods that the next stages (prototyping and testing/implementing) needed to address access to databases and the findability of links.

\section{Stage 2: Prototyping}

The prototyping stage entails generating ideas to solve problems that were discovered and analyzed in the observing stage. Some design cycle models call this stage "design" or "ideate." The ideas in the prototyping stage should not come from thin air and should flow from identified problems in the observe stage. If the prototyping stage is not informed by the observing stage, the new ideas will not address the problems users have and may even create new ones.

The literature on this stage of the design cycle emphasizes developing a lot of ideas for the defined problem and not looking for one single "right" idea from one individual. The Hasso Plattner Institute of Design at Stanford University describes this stage as a process of "going wide in terms of concepts and outcomes" (2010, p. 4). One method that particularly illustrates the approach and spirit of this stage is the practice of parallel design. In parallel design, members of a team, which could comprise students and librarians, independently create their paper prototype of a web page, addressing the problems identified in the observing stage. The team shares its paper prototypes and then creates a new prototype with the best ideas from each design. This approach embodies the "going wide" maxim by including many different ideas and concepts from multiple perspectives. Typically, parallel design is followed by usability testing of the resulting prototype. Using parallel design and usability testing in sequence is a way to 
compensate for the weaknesses of each method and illustrates the strength of a mixed methods approach. As in each stage, mixing multiple methods in the prototyping stage provides a more holistic approach toward the problems defined in the observing stage.

One of the goals for the library's website was to remove elements with low use or user value from the homepage and the survey results in the observing phase informed this goal. In the prototyping phase, we could have focused on the homepage, but library staff were also interested in broadening this goal to include the rest of the website. If users had difficulty finding certain links on the cluttered homepage, were they also struggling with finding resources on other parts of the website? We needed a method that would address the entirety of the website's pages. A usability test would be too narrow to evaluate the issue of clutter on a larger scale. We therefore conducted a content audit (also called a "content inventory"). A content audit involves itemizing each page on a website and assessing it by asking whether the content needs to be revised, removed, or moved to a new location ("Content inventory," 2013). In a content audit, staff may realize that some library services or information are not included on the website. This can generate a discussion of what services or information should be included and why. The content audit is likely to be perceived as the most time-intensive process for improving usability, mainly because it involves looking at everything on the website.

A content audit is appropriate for the prototyping stage of the design cycle because practitioners can conduct content audits after information on users is collected during the observing stage. Content audits are limited in that they do not directly ask for input from users, aside from library staff, about how to streamline the content. However, a content audit that integrates analytics data, gathered in the observing stage, strengthens the method by bringing users' behavioral data into the decisions made as a result of the audit. For instance, page views 
show which pages users skip over or rarely visit. For this content audit, I shared analytics data for all pages with library staff. They then performed a content audit in their assigned sections of the website. Sharing usage data may temper unrealistic perceptions of the importance of certain pages. Google Analytics showed our "News" category had only eight visits in 2015-2016. The low views did not necessarily mean we should remove the "News" category and the pages within, but it led to a discussion of the location of the "news" pages.

One way to structure a content audit is to create a form in Google Docs and assigning department heads a set of pages related to their department. The form serves as a springboard for conversations about pages to edit, revise, or delete. Establishing a means for discussion as part of a content audit is similar to parallel design because it involves people with different ideas and perspectives, and may provide a way to synthesize the best ideas on how to proceed.

Our content audit enabled us to streamline our site. We combined two pages dealing with government documents into one updated page. We caught outdated language about login procedures for our Interlibrary Loan service and moved a link to an FAQ about Interlibrary Loan to the Interlibrary Loan login page. The content audit also alerted us to a few instances of pages linked from multiple menu categories. For example, the "Reserves" page was linked from the "Find" and "Borrow" menu categories. Although it is common practice to have the same link in multiple menu categories, this project aimed to involve users in the categorization of links in an attempt to make the links easier to find.

To evaluate whether the current menu categories and placement of pages within each category made sense to our users, we used an additional method to obtain input from our users. Card sorting is a method that can be used to gather user input on content organization and labeling in the user interface (Rubin \& Chisnell, 2008). During a card sorting session, 
THE DESIGN CYCLE AND A MIXED METHODS APPROACH FOR IMPROVING

participants organize topics or web pages into categories that reflect their preferences. Users

have pre-existing mental models about where certain items should be located in different settings, be it links on a website or produce in a grocery store. In interface design, mental models help a user determine how to interact with a website and these models are based on previous experiences with other websites (Weinschenk, 2011). Card sorting generates data that can help reorganize a website to better fit users' expectations or mental models of how content is arranged.

There are two principal types of card sorting: "open” and "closed.” In “open" card sorting, participants organize web pages into categories they think are apt, then name each category they created in a way that they think correctly describes its pages ("Card sorting," 2013). This type of card sort is appropriate when library staff do not have predetermined categories or groups for the web pages. We decided against using this kind of card sorting because library staff had already identified their preferred categories. Our 2016 site had categories for "Find," "Borrow," "Services," "News," "Contact Us," and "About Us". Many of these categories overlap and could create confusion for a user. Interlibrary Loan, for instance, is a service, but is also a form of borrowing. "News" had had only two links and low page view numbers, so this category was a candidate for elimination or combination with another category. Library staff agreed on the following categories: "Find," "Services," "About Us," and "Help." We therefore used "closed" card sorting, where participants organize website pages into previously created categories (“Card sorting," 2013). Our goals for the card sort were to get users' input on which pages should be placed in which category. We also wanted to review the categories selected by library staff, so we included the following question at the end of a questionnaire answered by the users who participated in the card sort: "Do you think there 
should be a different category from the ones listed (Find, Services, About Us, Help)? If so, what would you name this category?"

Card sorting exercises can take place in person or online. We chose the online option because we were conducting our card sort in the summer and few students would be on campus. Instead, the online option could reach off-campus students. We used OptimalSort from Optimal Workshop, which required a $\$ 100 /$ month subscription, because of the ease of set-up and the robust reporting and analysis. Optimal Sort offers many analyses out of the box. The one that stood out as particularly useful was the Popular Placements Matrix, which highlights the most popular groupings. After reviewing the data, we placed our pages in the categories deemed most popular by the most participants. Placing the pages' organization in the user's hands felt liberating because the resulting data resulted in less disagreement between library staff about organization than might have been expected.

When recruiting participants for the card sort, we referred to a "questionnaire" and purposely avoided using the term "survey." We had asked users to take website surveys previously so instead of asking them a second time to take a survey, we thought using a different term would minimize potential fatigue or annoyance about completing a card sort. There were 35 participants, consisting of 15 faculty, 13 undergraduate students, one graduate student, and six staff members. The card sort included 25 pages.

There were clear trends in the Popular Placement Matrix (see Figure 1). For 15 pages, $70 \%$ of more of the participants placed it in the same category. For seven other pages, the percentage was $60 \%-69 \%$. For the remaining three pages, the percentage was $49 \%-51 \%$. One of these three was the "Reserves" page, which participants placed in two categories in similar proportions: $51 \%$ in "Find" and " $46 \%$ " in "Services." 


\section{Popular Placements Matrix}

Journals by Title
Articles and Databases
Films
Government Documents
Music Library
Special Collections
Course Guides
New and Recommended
$\quad$ Digital Commons
Reserves
FLEX Delivery
Interlibrary Loan
Locker \& Carrel Reservations
Renew/My Library Account
Staff and Departments
Library Blog
Hours
Library Newsletter
Library Policies
Borrowing Policies
Ask a Librarian
FAQs
Submit a Suggestion
Video Tutorials
Library Floor Maps

\begin{tabular}{|c|c|c|c|c|}
\hline Find & Services & About Us & Help & unsorted \\
\hline $94 \%$ & $6 \%$ & & & \\
\hline $89 \%$ & $11 \%$ & & & \\
\hline $86 \%$ & $14 \%$ & & & \\
\hline $86 \%$ & $14 \%$ & & & \\
\hline $74 \%$ & $20 \%$ & $6 \%$ & & \\
\hline $71 \%$ & $29 \%$ & & & \\
\hline $69 \%$ & $20 \%$ & & $11 \%$ & \\
\hline $69 \%$ & $26 \%$ & $6 \%$ & & \\
\hline $63 \%$ & $29 \%$ & $9 \%$ & & \\
\hline \multirow[t]{2}{*}{$51 \%$} & $46 \%$ & & $3 \%$ & \\
\hline & $97 \%$ & $3 \%$ & & \\
\hline $9 \%$ & $89 \%$ & & $3 \%$ & \\
\hline $3 \%$ & $74 \%$ & $11 \%$ & $11 \%$ & \\
\hline $14 \%$ & $60 \%$ & $3 \%$ & $23 \%$ & \\
\hline $3 \%$ & & $91 \%$ & $6 \%$ & \\
\hline $3 \%$ & $9 \%$ & $80 \%$ & $9 \%$ & \\
\hline $3 \%$ & $6 \%$ & $74 \%$ & $17 \%$ & \\
\hline \multirow[t]{6}{*}{$3 \%$} & $23 \%$ & $71 \%$ & $3 \%$ & \\
\hline & & $63 \%$ & $37 \%$ & \\
\hline & $14 \%$ & $51 \%$ & $34 \%$ & \\
\hline & $20 \%$ & $3 \%$ & $77 \%$ & \\
\hline & $3 \%$ & $20 \%$ & $77 \%$ & \\
\hline & $14 \%$ & $20 \%$ & $66 \%$ & \\
\hline $17 \%$ & $20 \%$ & $3 \%$ & $60 \%$ & \\
\hline $17 \%$ & $3 \%$ & $31 \%$ & $49 \%$ & \\
\hline
\end{tabular}

Figure 1. Optimal Workshop's Popular Placement Matrix. Percentages represent the proportion of students placing a page in the same category.

Overall, participants voiced approval of the proposed categories, deeming them comprehensive and easy to understand. After sharing the results with library staff for discussion, 
THE DESIGN CYCLE AND A MIXED METHODS APPROACH FOR IMPROVING

the library renamed the categories and reassigned several web pages to different categories, based on the users' responses.

Card sorting is decontextualized, which is a limitation, because the users are not using the website as they put pages into categories. Card sorting is also a form of self-reporting, but quantitative analysis of the data can show the most popular placements. Card sorting pairs especially well with content audits as an audit provides an updated list of pages to use in the card sort. This method collects feedback from users and thereby acts as a counterbalance to the library staff-dominated input of content audits.

Usability testing can be applied as a design method in both the prototyping and the testing/implementing stages of the design cycle, which can be confusing. There are two processes at play with usability testing: creating the usability test and conducting the usability test with users. Separating usability testing into two distinct stages of the design cycle emphasizes the importance of deliberation in creating the tasks or questions for the usability test in the prototyping phase before conducting usability testing in the testing/implementing phase. The observing stage plays an essential role by giving a librarian a baseline to design tasks for the usability test. How would a librarian design a usability test if they did not know users' key tasks or difficulties they have? Without that knowledge, a usability test might include tasks that interest librarians, but do little to explore a user's needs. For instance, pursuing an uninformed design of a usability test guided by a librarian's interest might create a task such as performing an advanced search for a journal using an ISSN. Such a task might be valuable and interesting to a librarian but perhaps not to a student. This kind of uninformed task design amounts to wasted effort because it ends up addressing an imagined need or concern instead of users' actual needs and concerns. 
In the observing stage, the Wyndham Robertson Library collected data from users that enabled it to begin designing tasks for the usability test. The survey results in the observing stage showed that users wanted an easier way to access databases, a less cluttered homepage, and a more readable layout or design. We were intentional in designing tasks that would hopefully address and tease out difficulties users had with the website. The analytics findings from the observing stage also helped us select tasks for the usability test. The analytics showed that the databases page was used the most, so the test design had a section of tasks dealing with databases. Other tasks included using the catalog to find books and DVDs, and checking the user's library account for checked-out books. Additional tasks were finding journals, finding librarians by name or subject area, and finding hours of operation.

Three Work-Study students tested the draft of the usability tasks to make sure the questions were clear and comprehensible. They confirmed the importance of certain tasks (e.g. finding the "My Account" link, finding databases) by reporting a high frequency of questions about these tasks. Being previously trained by the head of Circulation to answer basic reference questions, the Work-Study students had little difficulty completing nearly all of the tasks in the usability test. However, they struggled somewhat finding librarians by subject.

Going "wide" in the prototyping stage meant using a mix of methods that included ideas and perspectives from both library staff and users. Including multiple groups in the prototyping phase meant there was a decentralized generation of ideas. By using a content audit and card sort, ideas did not flow from only one person or one group, and users played a role as co-creators or co-designers. In addition to generating a broad spectrum of ideas, being intentional in the prototyping phase entailed analyzing all the data collected in the observing phase and using the analysis to guide the design ideas in the prototyping stage. 
The appropriate method for a library in the prototyping stage depends on the goals or domain of the project. For a broader goal such as improving the categorization or findability of pages, a content audit followed up by a card sorting exercise for users is a suitable option. If the usability problem is more defined (e.g. setting up a clear process on the website for scheduling an appointment with a librarian), creating a few prototypes to test with students is more appropriate. The prototypes can either be functioning web pages or paper mock-ups that simulate the process of scheduling an appointment. Asking students to indicate their preference among the prototype pages and whether anything is unclear about them drive the process of creating a better prototype. The most-recent prototype can be tested until most users are able to use it without difficulty. A broad goal such as findability of pages can be paired with a more refined goal such as the library appointment scheduler by placing the page for library appointments in the card sort to see where most users would look to find this service. Libraries should include users in the prototyping stage so the ideas from this stage directly address users' difficulties and acknowledge their preferences.

\section{Stage 3: Testing/implementing}

In this stage, librarians introduce prototypes to users and facilitate their interactions with each one. The testing/implementing stage is an opportunity for learning even more about users and developing additional empathy while watching how they interact with prototypes. Watching the effectiveness of the prototype in resolving usability problems makes this "rubber meets the road" stage arguably the most exciting one. It can be gratifying to see students use a newly designed element to complete a task as intended. Another useful, and sometimes bewildering, aspect is observing unexpected behavior and thereby learning more about users, which can lead to 
developing a solution to a previously unknown problem. Above all, perhaps the biggest reward is seeing how the design stages cascade into each other and provide valuable insights into improving usability.

Choosing a method in this stage depends on the goal. If a library is looking for input on a site's general design, accessibility, and usability, a heuristic evaluation is a good match.

Heuristic evaluations are typically conducted by a usability expert, broadly defined as someone with experience of conducting UX research and observing user behavior. A heuristic evaluation checks for adherence to usability guidelines and principles of human-computer interaction (Harley, 2018). A heuristic evaluation analysis provides a list of potential usability issues, which may be different from those found in usability testing, so a heuristic evaluation should not be used as a substitute for usability testing ("Heuristic evaluations", n.d.). A few common heuristics include remaining consistent in user interface design, minimizing the number of steps a user has to take to complete a task, and avoiding unclear language (Douglas, 2017).

If a library wants to address a defined problem or gain insight on how users complete specific tasks, a usability test is a better choice as it lets a librarian choose the tasks to test with users. A usability test provides a window into the approach and thoughts of users. During usability testing, a participant completes tasks on the website while a facilitator takes notes. Web usability tests often follow a think-aloud protocol where participants narrate or verbalize their thoughts while working through tasks. These tests expose the pain points a participant encounters with key tasks and through "thinking out loud" the facilitator hears the participant's thoughts during the task. Recording these tests via screen capture software allows librarians to review and discuss the data. 
Usability testing in the testing/implementing stage allows for a unique window into behavior otherwise not discoverable with methods such as surveys, interviews, or focus groups. It is behavioral and contextual because a practitioner observes users as they complete a task on the actual website, in contrast with other methods (e.g. surveys, interview) that are attitudinal and decontextualized because the practitioner gathers information from users about their feelings or attitudes about the website at a time when they are not using it. The testing/implementing stage generates a unique type of data and is an essential part of the design cycle.

Usability testing is a good method for addressing defined problems with specific tasks, but it can also explore other features of a site or system. For instance, library staff might know that most of their students are unaware of how to renew books by logging into the "My Account" section. The library staff might not know whether students are aware they can update their personal information in the "My Account" section. Usability testing could address the known problem of renewing books with a task and explore students' awareness of the feature by asking them to update their personal information during the test. This would be confirmatory and exploratory research.

Usability testing has the limitations of being an artificial environment and an approximation of what a user would do and how a user would behave. Also, the sampling of tests may not be representative (Rubin \& Chisnell, 2008).

A variation on the classic usability testing method is guerrilla usability testing. In guerrilla usability testing, participants are not recruited in advance and the testing has fewer tasks than a classic usability test (Adiseshiah, 2018). Also, guerrilla testing can be used on more primitive prototypes. For example, a facilitator can present sketches or paper prototypes of designs to users and ask them how they would perform a task on the prototypes. Alternatively, 
this shorter method can also be used with fully functioning prototypes (e.g. a developed website) in a similar way as classic usability testing, except with fewer tasks. One advantage of guerrilla usability testing is the ease of finding participants for testing. There is no formal recruitment process (e.g. creating fliers, advertising incentives to participate in a test). Using the guerilla method, a facilitator approaches a potential participant, explains their objective (e.g. testing a feature on a website), and jumps directly into the test. With permission, they might record the participant using the website. A limitation of guerrilla usability testing is that the facilitator spends less time and tests fewer tasks than classic usability testing. This shorter method might be more appropriate for a library staff with time constraints. Libraries preferring frequent and short usability tests instead of infrequent and more extensive tests may prefer this method. Guerrilla testing is also useful for libraries seeking users' perspective on rough layouts of web pages.

Using the survey and analytics results from the observing staging, the Wyndham Robertson Library had a list of defined problems and a strong interest in observing users attempt to find databases, log into their accounts, and perform other tasks. As mentioned, the data collected from the observing stage informed our design of the usability test in the prototyping stage, and we felt that our usability test addressed defined problems. After receiving IRB approval to ensure the methods, format, content, and test conditions provided anonymity and safety, the library set up individual tests through appointments and met our goal of testing 10 students in spring of 2016. This number fit with Rubin and Chisnell's (2008) recommendation to test at least eight participants. Nielsen and others (2000; "Recruiting usability test participants," n.d.) estimate that the majority of usability problems are identifiable with four or five participants, but this low number poses difficulties for obtaining a representative sample. 
The 2016 usability tests had students find books and DVDs in the catalog, log into their accounts, determine whether the library held specific journals and in which format, find specific databases, find contact information for specific librarians, and determine the library's hours of operation for the following week. In addition to completing tasks, we asked students to preview a prototype databases page. This was the "A-Z" list of databases available through our subscription to Springshare's LibGuides platform, which we considered a clean and simple alternative to the current page. At the end of the tasks, we asked students for their impressions of the prototype databases page, which of the database pages they preferred, and why.

Most of the participants took what we considered an "expert" path to these questions, which involved using the fewest clicks and finding the answers quickly and on their first attempt. The pain points during the tests echoed the responses in the homepage survey because many students struggled with tasks involving finding articles and databases. Some users had difficulty finding a subject-specific database and librarians with a subject specialty. A small set of users struggled slightly determining where to start an article search.

For each task, Wyndham Robertson Library librarians had ideas about the ideal or intended way for a participant to complete a task. We had put thought into creating elements on different pages for quick and easy access to resources. For instance, we had a "Subject" tab on the databases page with lists of hyperlinked subjects, each linking to a LibGuides page with a subject-specific list of databases (see Figure 2). Despite our efforts, many of our test participants did not click on this tab and looked for databases in circuitous or unexpected ways. 


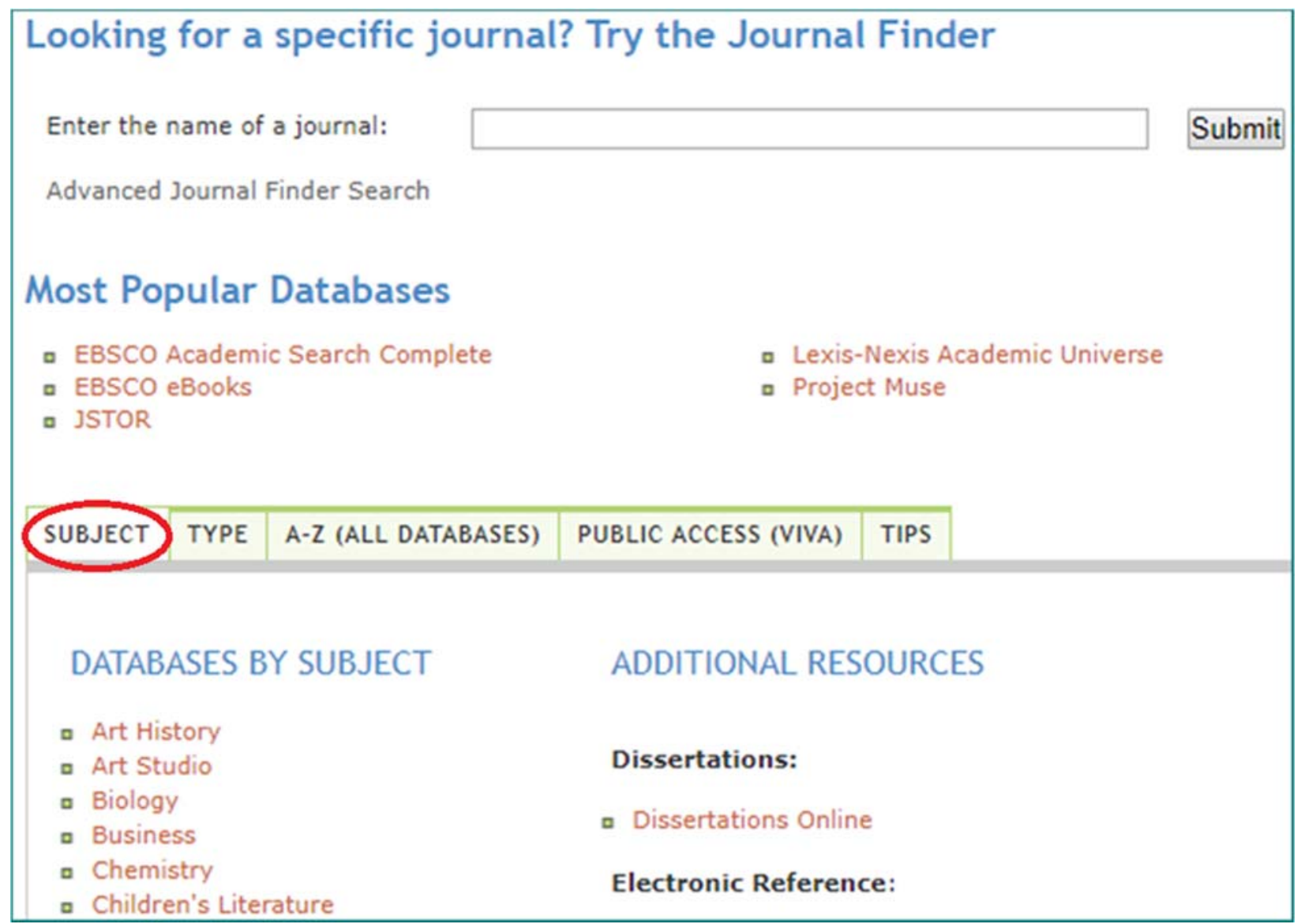

Figure 2. Original databases page.

After reviewing the prototype databases page (see Figure 3), participants commented on both and all preferred the prototype (see Table 2). 


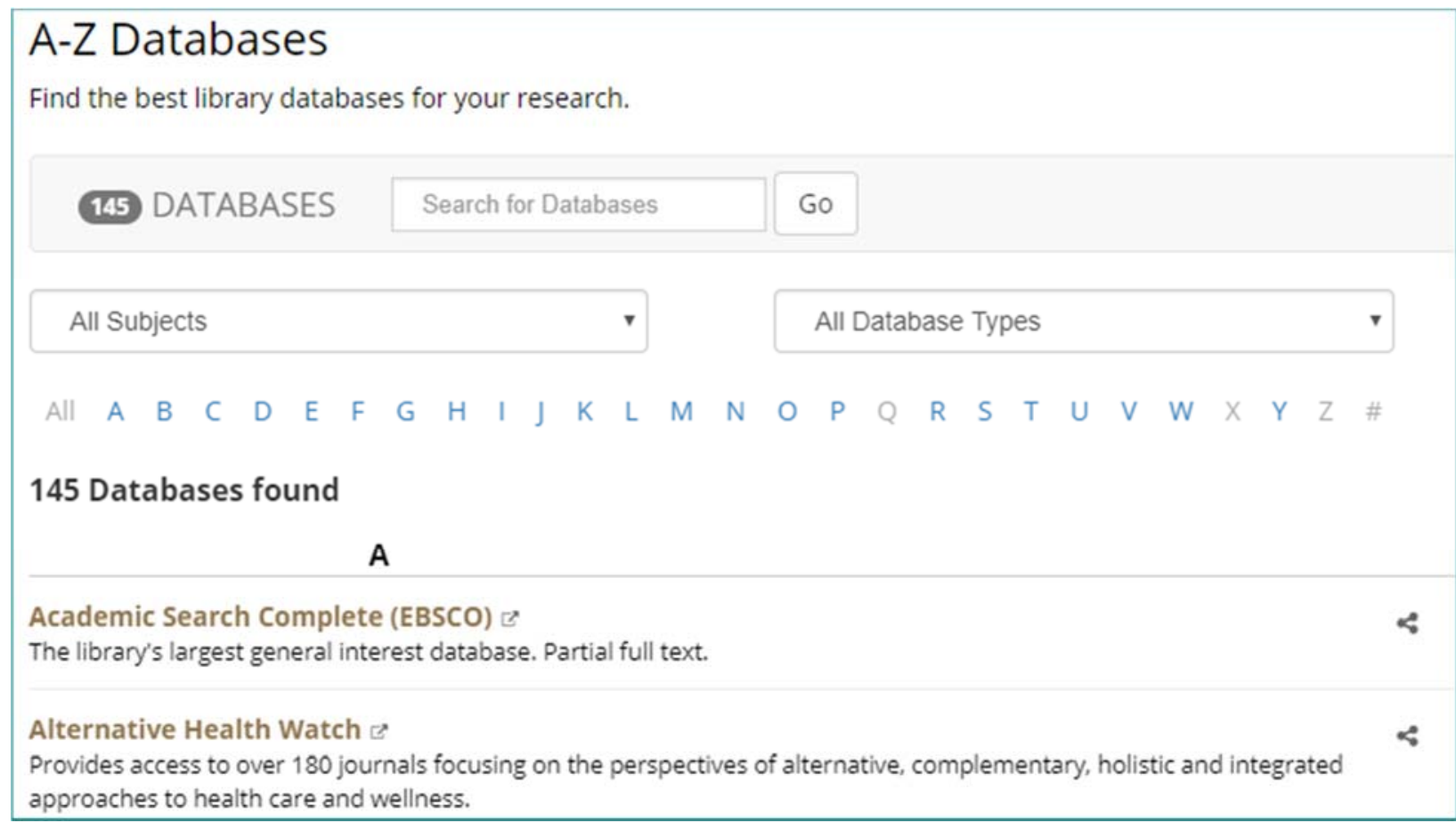

Figure 3. Prototype databases page: Springshare's A-Z List.

Table 2. Student responses to the original and prototype databases pages.

\section{Student responses}

\begin{tabular}{|l|l|}
\hline Original databases page & Prototype A-Z databases page \\
\hline - Takes effort to find something. & $\begin{array}{l}\text { I like the format and being able to search } \\
\text { for a database by title. }\end{array}$ \\
- The page is confusing. & $\begin{array}{l}\text { I like the limiters, specifically for } \\
\text { database type because I like being able } \\
\text { - There's a lot going on. }\end{array}$ \\
- There are a lot of tabs. & to see primary sources. \\
- The page is hard to navigate without a & $\begin{array}{l}\text { This database page was more } \\
\text { direct/obvious }\end{array}$ \\
- This page doesn't allow you to apply & I like the aesthetic. It looks more \\
two limiters at the same time the way & current. \\
the prototype does. & \\
\end{tabular}

These tests were valuable for identifying and later addressing the difficulties users had.

After reviewing the results of a usability test, library staff can return to the prototyping stage and propose changes to the website with the intention of making certain tasks easier. Moving from the testing/implementing stage to the prototyping stage is an example of the iterative and non- 
THE DESIGN CYCLE AND A MIXED METHODS APPROACH FOR IMPROVING

linear nature of the design cycle. Results from one stage may be used to inform actions in another.

Our results from the testing/implementing stage of spring 2016 informed our actions in the prototyping stage. After reviewing the usability test results of 2016, we noticed that many students were unaware of the tabs on the database page, which organized databases by subject, by type (e.g. newspapers, encyclopedia), and by A-Z.

After deliberation, the library decided to replace the current databases page with the Springshare LibGuides A-Z databases page. The cleaner interface of the LibGuides A-Z list and its ability to dynamically generate subject- or type-specific lists of databases via two simple dropdown menus made it seem more user-friendly. Moreover, the participants' positive responses to the prototype databases page supported the change.

To make databases more accessible from the homepage, we also renamed our "Articles" tab as "Articles \& Databases." We also added a database dropdown menu to this tab so a user could more easily access databases from the homepage. In addition to website changes related to databases, we wanted to address the findability of subject-specific librarians. We created a dropdown menu under the header "Find Your Subject Librarian" with a list of subjects, each linked to the subject-specific librarian's page with contact information. We placed these dropdown menus on the "Staff and Departments" page and the "Ask a Librarian" page. We also created a new page that had an A-Z list of subjects showing the corresponding librarian for each subject and their contact information.

These enhancements completed our second prototyping stage. A year later, we were interested in knowing whether they had made an impact on users' experiences, so we ran the same usability test in spring 2017 with IRB approval, again with 10 undergraduates. The 
usability scores in these categories showed marked improvements for two specific tasks (see

Table 3). Improvements in finding databases and subject-specific librarians indicated the prototypes were a success. There was little variation between the results from the 2016 and 2017 tests in other task categories (e.g. finding books, logging into an account, finding library hours).

Table 3. Comparison of 2016 and 2017 task results.

\begin{tabular}{|l|l|l|l|}
\hline Task & 2016 result & Enhancement & 2017 result \\
\hline $\begin{array}{l}\text { Finding a subject } \\
\text { specific librarian }\end{array}$ & $60 \%$ success & $\begin{array}{l}\text { Adding librarian } \\
\text { by subject page } \\
\text { and librarian by } \\
\text { subject dropdown } \\
\text { menu }\end{array}$ & $90 \%$ success \\
\hline $\begin{array}{l}\text { Finding subject } \\
\text { specific databases }\end{array}$ & $\begin{array}{l}\text { Replace databases } \\
\text { page with simpler, } \\
\text { cleaner, dynamic } \\
\text { page from } \\
\text { Springshare }\end{array}$ & $100 \%$ success \\
\hline
\end{tabular}

\section{Limitations and further research}

This article examines the design cycle in the context of a website redesign, so the examples of methods and descriptions of how they were deployed in our project are oriented towards website design. However, the design cycle can be applied to a variety of library projects and is not limited to projects involving websites. Focusing on one project area (our website redesign) was intended to make the principles of the design cycle easier to understand by way of specific examples.

This article does not attempt an exhaustive treatment of all usability methods. Instead, it explores popular methods based on a survey of the library literature. The aim of this article is to illustrate the principles of the design cycle, the popular methods associated with each stage of the cycle, and in doing so make it easier to choose methods based on the needs of a project. 
Moreover, explaining the limitations of certain methods is intended to encourage a mixed methods approach in each stage of the design cycle.

Further research could attempt to validate the effectiveness of the design cycle with empirical evidence. Throughout this case study, there is an emphasis on following the order of the design cycle and using different methods in a specific sequence. To test the significance of the sequence, researchers could run two usability projects using methods in different sequences and compare the results by doing usability testing at the end of the projects. For instance, does conducting a content audit before performing a card sort increase findability of pages of a site? In other words, do specific methods need to be used in a certain order to obtain the best results? This case study also stressed the importance of using multiple methods. Further research might explore the efficacy of using a mixed methods approach by conducting two usability projects; one using multiple methods in each stage of the design cycle and the other using a single method in each stage of the design cycle.

\section{Recommendations for applying a design cycle approach}

An understanding of the design cycle gives a librarian many advantages when undergoing usability projects. First, the design cycle provides a structure to follow during the project with clear steps:

- To make anything more usable, it is necessary to understand and empathize with users. What do they want? What are they struggling to do when using a service?

- Using data to understand and empathize, begin brainstorming ideas for the project.

- While brainstorming, recruit users to generate ideas to make a service more usable. These ideas lead to users and librarians working as co-designers in creating prototypes to test.

- The next stage is testing a prototype and collecting data from the test. 
- The test results help to understand and empathize with users, which can then lead back to the brainstorming stage.

- These stages can be repeated, with the intention of making the system better and better in each iteration.

This structure can be applied to any library design project.

Understanding the various types of methods, the limitations of each method, what kind of data they collect, and how they relate to each other allows a practitioner to pair methods to compensate for the weaknesses of a single method. As described above, surveys and interviews (attitudinal category) are a useful method for hearing users' preferences or thoughts. However, the methods in this category do not show how users actually interact with a website or service, so a contextual method (e.g. usability tests, analytics) is needed to counterbalance the findings from the attitudinal category. Both types provide valuable data, but a practitioner should not rely exclusively on a single type.

Table 4 provides a checklist to simplify the process of selecting methods from different categories.

Table 4. Design cycle and mixed methods checklist.

\section{DESIGN CYCLE \& MIXED METHODS CHECKLIST}

For each stage select a category of method from Type A AND Type B. Strive to use all four method categories for a project. Stages cannot be skipped.

The user must be involved in some way in each stage.

\begin{tabular}{|l|c|c|c|c|}
\hline & \multicolumn{2}{|c|}{ TYPE A } & \multicolumn{2}{c|}{ TYPE B } \\
\hline STAGES & Attitudinal & Qualitative & Behavioral/Contextual & Quantitative \\
\hline Observe & $\square$ & $\square$ & $\square$ & $\square$ \\
\hline Prototyping & $\square$ & $\square$ & $\square$ & $\square$ \\
\hline Test/Implement & $\square$ & $\square$ & $\square$ & $\square$ \\
\hline
\end{tabular}


Questions about the selection of methods that a library should ask before and during a usability project include:

- What methods are appropriate for gathering data about specific usability problems or issues?

- Does each method allow users to comment on new or previously-unknown usability issues?

- Is there another method that could supplement the data gathered from the first method?

- Are there other methods that were overlooked? Why would these not be useful?

- How can the findings from this stage of the design cycle inform the actions in the next stage?

There are obviously time constraints on librarians, particularly those working alone on usability projects. These limitations make it more difficult to apply multiple methods during a project, but also make choosing an appropriate method more important.

\section{Conclusion}

"A single twig breaks, but the bundle of twigs is strong" (Tecumseh, 1795, as cited in Philip, 2006, p. 27).

In this case study, our library tried to avoid relying too heavily on one method during each stage of the design cycle. A single method did not dictate the direction and completion of the project. The methods were all connected and the project was guided in each stage by the findings obtained with multiple methods. The shortcomings of each method were addressed by using different categories of methods with different strengths and weaknesses. The data gathered from this mix of methods revealed usability problems and helped to set goals and create an action plan to improve usability. Perhaps most importantly, library users were included during each stage of 
the design cycle. Their preferences determined the changes we made. Using the design cycle for projects creates an order, a structure, and a logic that can guide libraries through the complex process of choosing what to test, how to test, and how to apply the results of testing. 


\section{References}

Adiseshiah, E. G. (2018, May 21). Guerrilla usability testing: How to introduce it in your next usability project. Retrieved from https://usabilitygeek.com/guerrilla-usability-testinghow-to/

Brown, T. (2009). Change by design: How design thinking transforms organizations and inspires innovation. New York, NY: Harper Collins.

Card sorting. (2013, October 9). Retrieved from https://www.usability.gov/how-to-andtools/methods/card-sorting.html

Carter, D. S., Tolliver, R. L., Fisher, J. E., Chapman, S. E., Price, R. M., Krolikowski, L. E., ... Haines, A. L. (2005). Website redesign and testing with a usability consultant: Lessons learned. OCLC Systems \& Services: International Digital Library Perspectives, 21(3), 156-166. https://doi.org/10.1108/10650750510612362

Content inventory. (2013, September 6). Retrieved from https://www.usability.gov/how-to-andtools/methods/content-inventory.html

Design thinking for libraries. (n.d.) Retrieved from http://designthinkingforlibraries.com/

Dominguez, G., Hammill, S. J., \& Brillat, A. I. (2015). Toward a usable academic library web site: A case study of tried and tested usability practices. Journal of Web Librarianship, 9(2/3), 99-120.

https://doi.org/10.1080/19322909.2015.1076710

Donaldson, S. I., \& Grant-Vallone, E. J. (2002). Understanding self-report bias in organizational behavior research. Journal of Business and Psychology, 17(2), 245-260. https://doi.org/10.1023/A:1019637632584

Douglas, S. (2017, December 6). 7 usability heuristics that all UI designers should know. Retrieved from https://usabilitygeek.com/usability-heuristics-ui-designers-know/

Fagan, J. C. (2014). The suitability of web analytics key performance indicators in the academic library environment. The Journal of Academic Librarianship, 40(1), 25-34. https://doi.org/10.1016/j.acalib.2013.06.005

Gibbons, S. (2016, July 31). Design thinking 101. Retrieved from https://www.nngroup.com/articles/design-thinking/

Goward, C. (2012). You should test that: Conversion optimization for more leads, sales and profit or the art and science of optimized marketing. Indianapolis, IN: Wiley. 
Harley, A. (2018, February 25). UX expert reviews. Retrieved from https://www.nngroup.com/articles/ux-expert-reviews/

Heuristic evaluations and expert reviews. (n.d.). Retrieved from https://www.usability.gov/how-to-and-tools/methods/heuristic-evaluation.html

International Baccalaureate. (2014). International Baccalaureate middle years programme subject brief. Retrieved from https:/www.ibo.org/globalassets/digitaltookit/brochures/myp-brief_design 2015.pdf

Jaeger, R. G., \& Halliday, T. R. (1998). On confirmatory versus exploratory research. Herpetologica, 54(Suppl.), S64-S66.

Johnson, R. B., \& Onwuegbuzie, A. J. (2004). Mixed methods research: A research paradigm whose time has come. Educational researcher, 33(7), 14-26. https://doi.org/10.3102/0013189X033007014

Johnson, R. B., \& Turner, L. (2003). Data collection strategies in mixed methods research. In A. Tashakkori \& C. Teddlie (Eds.), Handbook of mixed methods in social and behavioral research (pp. 297-320). Thousand Oaks, CA: Sage Publications.

Kalaichandran, A. (2017, August 3). Design thinking for doctors and nurses. The New York Times. Retrieved from https://www.nytimes.com/2017/08/03/well/live/design-thinkingfor-doctors-and-nurses.html

Liedtka, J., Bennett, K. B., \& King, A. (2013). Solving problems with design thinking: Ten stories of what works. New York, NY: Columbia University Press.

Manzari, L., \& Trinidad-Christensen, J. (2006). User-centered design of a web site for library and information science students: Heuristic evaluation and usability testing. Information Technology and Libraries, 25(3), 163-169.

Nielsen, J. (2000, March 19). Why you only need to test with 5 users. Retrieved from https://www.nngroup.com/articles/why-you-only-need-to-test-with-5-users/

Nielsen, J. (2001, August 5). First rule of usability? Don't listen to users. Retrieved from https://www.nngroup.com/articles/first-rule-of-usability-dont-listen-to-users/

Nielsen, J. (2012, June 4). How many test users in a usability study? Retrieved from https://www.nngroup.com/articles/how-many-test-user

Oldham, B. W. (2008). Focus groups and usability testing in redesigning an academic library's web site. Journal of Web Librarianship, 2(2-3), 219-246. 
THE DESIGN CYCLE AND A MIXED METHODS APPROACH FOR IMPROVING

USABILITY: A CASE STUDY

https://doi.org/10.1080/19322900802205866

Philip, N. (2006). The great circle: A history of the first nations. New York, NY: Clarion Books.

Hasso Plattner Institute of Design. (2010). An introduction to design thinking process guide.

Retrieved from https://dschool-

old.stanford.edu/sandbox/groups/designresources/wiki/36873/attachments/74b3d/ModeG uideBOOTCAMP2010L.pdf

Recruiting usability test participants. (n.d.). Retrieved from https://www.usability.gov/how-toand-tools/resources/ucd-map.html

Rogers, R., \& Preston, H. (2009). Usability analysis for redesign of a Caribbean academic library web site: A case study. OCLC Systems \& Services: International Digital Library Perspectives, 25(3), 200-211. https://doi.org/10.1108/10650750910982584

Rohrer, C. (2014, October 12). When to use which user-experience research methods. Retrieved from https://www.nngroup.com/articles/which-ux-research-methods/

Rubin, J., \& Chisnell, D. (2008). Handbook of usability testing: How to plan, design, and conduct effective tests (2nd ed.). Indianapolis, IN: Wiley.

Schmidt, A., \& Etches, A. (2014). Useful, usable, desirable: Applying user experience design to your library. Chicago, IL: ALA Editions.

User-centered design process map. (2013, December 18). Retrieved from https://www.usability.gov/how-to-and-tools/resources/ucd-map.html

Weinschenk, S. (2011, October 8). The secret to designing an intuitive UX : Match the mental model to the conceptual model. Retrieved from https://uxmag.com/articles/the$\underline{\text { secret-to-designing-an-intuitive-user-experience }}$

Wyndham Robertson Library mission (n.d.). Retrieved from http://library.hollins.edu/mission/

Zaugg, H., Terekhova, V., \& Rennick, B. (2015). Evaluation of an academic library's liquid designed website. Evidence Based Library and Information Practice, 10(4), 200-214. http://hdl.lib.byu.edu/1877/3539 